\section{EL CÓMIC ESPAÑOL DESDE 1995}

\author{
Juan Manuel Díaz de Guereñu
}

Universidad de Deusto, San Sebastián

\section{THE SPANISH COMIC STRIP SINCE 1995}

\begin{abstract}
In the last fifteen years comic has changed dramatically in Spain. The small size of the comics industry in the Spanish market doesn't allow comic creators to turn his job into a profession, but the medium has attained prestige, critical attention on the cultural spaces and a place in the bookstores. Those changes are the consequence of some significant facts of the period: after the extinction of former comic magazines, comic books substituted them as the first format for comics edition, and a number of critical fanzines and self-edited fanzines and magazines were published by the authors themselves. Newborn and independent smallpress, more focused on the aesthetic values than on the economic profits of comics edition, have defined the new author comic, often printed in the format of books and associated to the "graphic novel" label.
\end{abstract}

KEY WORDS: critical fanzines; author comics; independent publishers; graphic novel.

En la última década y media, la situación del cómic en España ha cambiado de forma notoria. El lector se ha habituado a ver una amplia oferta de títulos a la venta en grandes superficies 0 en librerías generalistas y tiende a olvidar que hace poco solo asomaban a sus estanterías, si acaso, unas pocas series de consumo masivo, como Mortadelo y Filemón o Asterix. Ya no es excepcional, sino poco menos que habitual, ver crítica de cómics en suplementos culturales de periódico 0 en revistas. $Y$ existe un consenso antes impensable que reconoce al medio capacidad para expresar ideas y sentimientos de interés general y para suscitar efectos estéticos tan eficazmente como otras formas de expresión, de modo que, aunque asoman periódicamente a los foros públicos opiniones denigratorias o descalificaciones globales, estas son percibidas ya no como reflejo de una opinión mayoritaria, sino casi como residuos arcaicos y miopes de formas de pensar ya periclitadas.

Esta nueva valoración social del medio, o de sus títulos más sobresalientes, acompaña a los nuevos formatos que predominan en él. En este periodo, el cómic ha aproximado su presentación a la del libro, lo que ha contribuido sin duda a tal reconsideración de su valía estética.
RESUMEN: En los últimos quince años, el cómic ha cambiado mucho en España. Aunque el escaso peso de la industria del cómic no permite a los autores vivir como profesionales, el medio ha ganado prestigio, atención crítica en las páginas culturales y un lugar en las librerías. Dichos cambios son consecuencia de algunos hechos significativos del periodo: tras la desaparición de las revistas, las sustituyeron cuadernillos o comic-books como soporte fundamental del cómic, y proliferaron revistas críticas de aficionados y fanzines 0 revistas autoeditadas por los autores. Nuevas editoriales, pequeñas e independientes, más atentas a los valores estéticos que a los comerciales, han definido el nuevo cómic de autor, a menudo identificado con el formato libro y la etiqueta "novela gráfica".

PALABRAS CLAVE: fanzines críticos, cómic de autor, editoriales independientes, novela gráfica.

Tales cambios no son, por supuesto, específicos del mercado español. De hecho, parecen ligados a una internacionalización imparable, que asegura mayor permeabilidad que nunca de los mercados nacionales del cómic a formatos, recursos narrativos y argumentos foráneos.

Lo que no parece que haya cambiado de igual modo en este periodo es la situación del cómic español, es decir, del creado por autores españoles y publicado por sellos editoriales de aquí. La industria local del cómic se dedica mayormente a traducir materiales importados de índole comercial y solo una parte menor de lo editado fue creado aquí. En consecuencia, los historietistas españoles siguen siendo en lo fundamental creadores voluntariosos u obcecados de obras que rara vez proporcionan ingresos que permitan considerar siquiera la perspectiva de una profesionalización. Solo unos pocos han logrado estatuto de profesionales o semiprofesionales del medio, por lo general haciendo humor de actualidad o trabajando para sellos editoriales foráneos, en particular norteamericanos y franceses. La historia de este periodo es también la de los expedientes a que hubieron de acudir para poder dibujar historietas. 
Documentar dichos cambios y tales rasgos permanentes, por mucho que parezcan claros al observador atento del mercado español, no es tarea sencilla. La industria española del cómic es de pequeño tamaño y notablemente opaca. Resulta imposible cuantificar con un mínimo rigor las cifras de venta o de negocio de cada sello. Cuando Dude, una editorial pequeña, empezó a hacer públicas las ventas de cada uno de sus títulos, el hecho fue destacado como excepción a la regla, derivado de un deseo de sus editores "de que los lectores se den cuenta de que somos 'otra cosa'", es decir, de una política editorial intencionadamente contra corriente (García, 1999: 25).

Los análisis de la producción editorial que realizan anualmente estudiosos del cómic (por lo general publicados en Internet y solo excepcionalmente impresos) reúnen datos significativos sobre el número de títulos publicados, el origen geográfico de los materiales o el formato en que se publican, es decir, sobre informaciones al alcance de todo lector, pero no aportan ninguna acerca de las ventas o los resultados económicos de cada empresa, que estas suelen ocultar. Los últimos informes publicados lamentan sistemáticamente que "las editoriales no suministran datos de ventas" (Harguindey, 2006: 79), su "secretismo" (Pons, 2008: 60) o su "oscurantismo en la información sobre ventas" (Pons, 2010; Guiral, 2006).

Por otro lado, los datos estadísticos que proporcionan otras fuentes, como el Informe sobre el comercio interior del libro que elabora la Federación de Gremios de Editores de España, presentan errores de bulto al cuantificar el número de títulos publicados, lo que suscita dudas razonables acerca de la exactitud de las cifras que ofrecen (Pons, 2008: 62-63). Probablemente el pequeño porcentaje que representa el cómic en el negocio editorial español, en torno al 3 por ciento, según dicho informe, y su reparto entre un buen número de sellos editoriales a veces no profesionalizados explican tales inexactitudes 0 imprecisiones.

En consecuencia, cualquier aproximación a la producción de cómics en España se tiene que contentar con describir los fenómenos más notables, sin cuantificarlos, es decir, sin que sea posible medir su real significación económica. Esto produce inevitablemente sesgos y malentendidos. Es muy probable, por ejemplo, que en términos económicos la publicación semanal de la revista de humor El Jueves o las reediciones constantes de las historietas de Mortadelo y
Filemón pesen mucho más que toda la producción de bastantes de los sellos editoriales que se dedican a publicar cómics, aunque ni una ni otras hayan contribuido a la diferente percepción del medio a que me referí arriba. Conviene no perder de vista esta realidad.

Ha de añadirse a dicha precaución la obligada cuando se presta atención, como es el caso aquí, a fenómenos culturales 0 sociales tan próximos que resulta difícil ponderar adecuadamente la importancia 0 el alcance de cada dato. El relato de estos últimos quince años que propongo no pasa de tentativa de aclarar algunos acontecimientos, en cuya descripción me han ayudado no poco algunos protagonistas o testigos amigos.

\section{FINAL DE UNA ÉPOCA}

En 1995 coincidieron varios hechos sintomáticos de un cambio de ciclo en el mercado del cómic español. Ese año, Norma dejó de publicar la revista Cimoc, tras 176 números aparecidos regularmente desde 1981. Según la nota del editor en su último número, llevaba años siendo un agujero "que tapar" (M artínez, 1995b). No fue la única cabecera cancelada en esa fecha, pues también dejó de aparecer, tras solo 14 números, la revista Viñetas, con la que Glénat España había intentado fijar para nuestro mercado su proyecto editorial. Tampoco su pérdida fue más sensible para el lector que otros muchos cierres de revistas en fechas anteriores. Pero Cimoc había sido una de las revistas que definió el periodo precedente, por la cualidad de sus contenidos y por el modelo de producción que representó.

Norma, agencia que luego se constituyó como editorial y, más adelante aún, como distribuidora, empleó Cimoc -y por un periodo más breve la revista Cairo- para la publicación seriada de historietas importadas o producidas aquí, que luego podía recopilar en álbum. La colección de álbumes Cimoc extra color fue la más nutrida de las que reunieron las series populares de la revista, que de ese modo eran explotadas comercialmente en dos formatos de publicación sucesivos. A los autores se les pagaba por 10 general una cantidad fija por página al publicar las entregas en la revista y el porcentaje sobre el precio de venta fijado como derechos de autor cuando se editaba el álbum. 
Tal modelo de publicación hizo crisis desde finales de los ochenta por un "cambio de hábitos" del lector (Martínez, 1995a), y no solo en el mercado español. En el francés, mucho más robusto, desaparecieron cabeceras antaño famosas -Pilote, Á Suivre, Circus, Métal Hurlant, etc.-, que las ventas ya no sostenían. Simplemente, a los lectores ya no les interesaba leer por entregas en revistas misceláneas y cuyos contenidos eran de interés variable las historias que pocos meses después podrían adquirir reunidas en álbum. La crisis del mercado de la bande dessinée francófona, agudizada por las consecuencias económicas de la primera guerra del Golfo en 1991, redujo fuertemente las posibilidades de exportar cómics españoles.

Las consecuencias fueron devastadoras para los autores, que vieron desaparecer la posibilidad de unos ingresos previos por la publicación seriada. En el mercado español, con este sistema se desvaneció en buena parte la posibilidad, ya muy pequeña, de hacer del cómic una profesión.

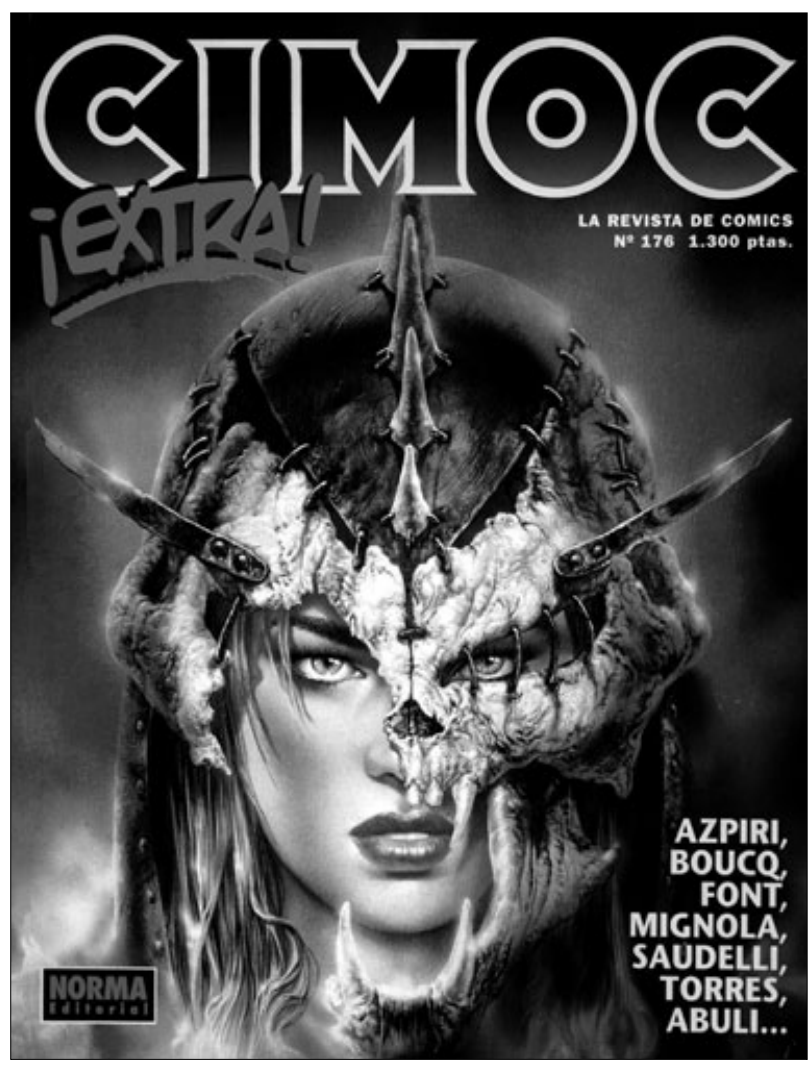

Imagen 1. Cimoc, $n^{\circ}{ }_{176}$, diciembre de 1995.
En los años que abren el periodo, la industria se mostró simplemente incapaz de proponer formatos de publicación económicamente viables y los autores de cómic, en su mayoría, dejaron de serlo o hubieron de buscar otros ingresos.

De la "avalancha editorial" (Altarriba, 2001: 317) de las revistas españolas de cómics en los ochenta solo quedaron en pie contadas cabeceras. El Vibora, que desde su aparición en 1979 fue estandarte de la contracultura y permitió la consolidación de la editorial La Cúpula (Dopico, 2005: 317-334), se convirtió en escaparate del cómic alternativo internacional, en particular del norteamericano, y en menor medida del nacional, y siguió publicándose hasta el año 2005.

Desde 1991 la acompañó Kiss Comix, una revista de cómic pornográfico de la misma editorial, que aún se publica (en junio de 2010 ha alcanzado los 225 números), tuvo unas ventas que rondaban los 20.000 ejemplares mensuales (García y Muñoz, 1998: 20) e incluso editó versiones francesa y norteamericana (Serrano, 2009). La relativa solidez comercial de Kiss Comix se debe obviamente a la índole de sus contenidos, para los que acaso resulta aliciente el lenguaje visual del cómic, pero su pervivencia apenas afecta al cómic español, aunque la revista haya servido a algunos dibujantes para probar el trabajo remunerado.

La revista El Jueves ofrece el ejemplo más notable de buen resultado comercial asociado a un género determinado, el humor de actualidad. Fundada en 1977, es la única superviviente de entre las revistas satíricas que abundaron en el periodo de la transición a la democracia y, con oscilaciones, ha mantenido una cifra de ventas que envidia cualquier producto impreso del cómic, pues cambió de siglo vendiendo entre 80.000 y 90.000 ejemplares semanales (Trama, 2002: 5). Esa sólida base le permitió ofrecer una serie de álbumes recopilatorios, Pendones del humor, vendidos en quiosco, y ampliarla con "ediciones más cuidadas, recopilaciones en tapa dura, los Magnums (libros de gran formato sobre temas 0 autores) y las ediciones de bolsillo, que alargan la vida de las obras" (Peonza, 2009: 193). El humor de actualidad se ha probado capaz, en suma, de conservar un reducto editorial que mantiene las pautas de producción habituales antes del hundimiento generalizado del sistema de las revistas. Una versión más modesta, local y agresiva del mismo humor la ofrece la revista TMEO, que 
ha publicado 110 números desde 1987 además de álbumes recopilatorios (Díaz de Guereñu, 2006: 29-31).

Estas contadas excepciones, mayormente ligadas a géneros de éxito, no desmienten, con todo, el dato fundamental. El cierre de Cimoc en 1995 certificó que la revista había dejado de ser el "soporte fundamental" del cómic español (Altarriba, 2001: 320). A cubrir el vacío que dejó acudieron diversas iniciativas que dibujaron el perfil del nuevo periodo.

\section{EL RECURSO DE LA GRAPA}

El mismo año 1995 adquirió hechuras de publicación impresa con su no 6 la revista Dolmen de información y crítica sobre el cómic, hasta entonces fanzine fotocopiado, la única que sigue publicándose quince años después (en mayo de 2010 llegó al no 175) y base de la editorial de igual nombre. También apareció la revista Slumberland, que hasta 1998 publicó 38 números mensuales y cuatro extras sobre "el mundo de la historieta", según rezó su lema de cabecera (Díaz de Guereñu, 2006a: 92-93). La publicó Camaleón, sello que se hizo cargo también de Dolmen entre 1996 y 1998 (V. García, 2004).

Camaleón comenzó a publicar en Barcelona en 1992. Era propiedad del colectivo Estudio Phoenix, un equipo de producción técnica que trabajó para editoriales mayores, y, más que como editorial, operó como "proveedor de servicios editoriales" (Pons, Porcel y Sorni, 2007: 252) para autores de cómics y aficionados estudiosos del medio. Así, hasta su cierre en 1998 publicó obras de Albert Monteys, David Muñoz y Luis Bustos, Javier Olivares, Santiago Sequeiros y Carlos Portela, entre otros, y un número sorprendente de revistas críticas simultáneamente, pues a las dos ya citadas se añadieron Neko y $U$.

El florecimiento de cabeceras críticas como las mencionadas y otras que las siguieron (Díaz de Guereñu, 2006a) es un fenómeno significativo. A la falta de revistas profesionales de y sobre cómics respondieron numerosas iniciativas de aficionados al medio, que a menudo empeñaron en la labor algo más que las precarias posibilidades de la fotocopia y la grapa. Dolmen y Slumberland coinciden además en formato y contenido. Eran revistas de tamaño reducido $(17 \times 26 \mathrm{~cm})$, impresas en blanco y negro salvo las cubiertas, grapadas y que se ocupaban de forma preferente, aunque no exclusiva, del cómic norteamericano, es decir, de los comic-books de superhéroes y sus variantes.

Formato y contenido de ambas revistas indican un cambio en los ejes de referencia de los nuevos lectores y críticos. Estos ya no miraban esencialmente al mercado francófono 0 al cómic europeo, sino al norteamericano. Posiblemente el cambio estaba ligado a la edad: a la generación de quienes estudiaron como segunda lengua el francés sucedía la de quienes estudiaron inglés y orientaron sus lecturas de cómics al mercado anglosajón. Y desde luego lo fundamentaba la diferencia de precio de los respectivos formatos dominantes. En 1995, el precio de venta de un álbum europeo en rústica rondaba las 1.000 pesetas. El comic-book, en cambio, se vendía a 175 pesetas y estaba mucho más al alcance de cualquier bolsillo juvenil.

A falta de estudios de mercado, la lógica induce a suponer que revistas y álbumes no supieron atraer a los lectores más jóvenes, que prefirieron lo que ofrecían los formatos más baratos del comic-book y luego del manga japonés, y

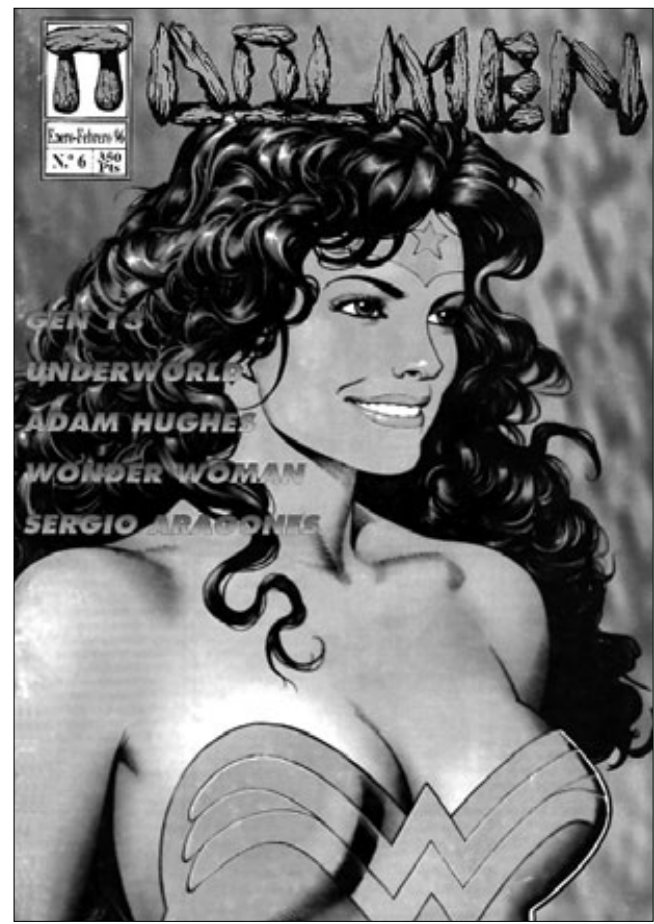

Imagen 2. Dolmen, $n^{\circ} 6$, con fecha de portada de enero-febrero de 1996 (en realidad, diciembre de 1995). 
tampoco lograron retener a los de más edad en número suficiente para seguir. Las editoras comerciales buscaron las licencias más rentables y hasta Norma privilegió al poco el material yanqui en lugar del europeo.

La aparición de dichas revistas críticas acompañó, pues, a un cambio en el formato preferido del lector. El álbum cedió el paso al comic-book o "cuadernillo seriado" (Altarriba, 2001: 321). Este se impuso además como "plataforma ideal de publicación para los jóvenes autores patrios" (Pons, Porcel y Sorni, 2007: 251). De tamaño similar al de las revistas descritas, impreso en monocromía, con cubiertas a color y veintitantas páginas grapadas por lo general, era el soporte de producción más barata. Podían costearlo incluso autores principiantes decididos a autoeditarse, a falta de editoras dispuestas a recibirlos, para quienes también era más fácil dibujar su contenido que el del álbum tipo de cuarenta y tantas páginas a color.

Camaleón fijó el modelo para un nuevo sistema de producción, que vino a sustituir precariamente a la edición comercial

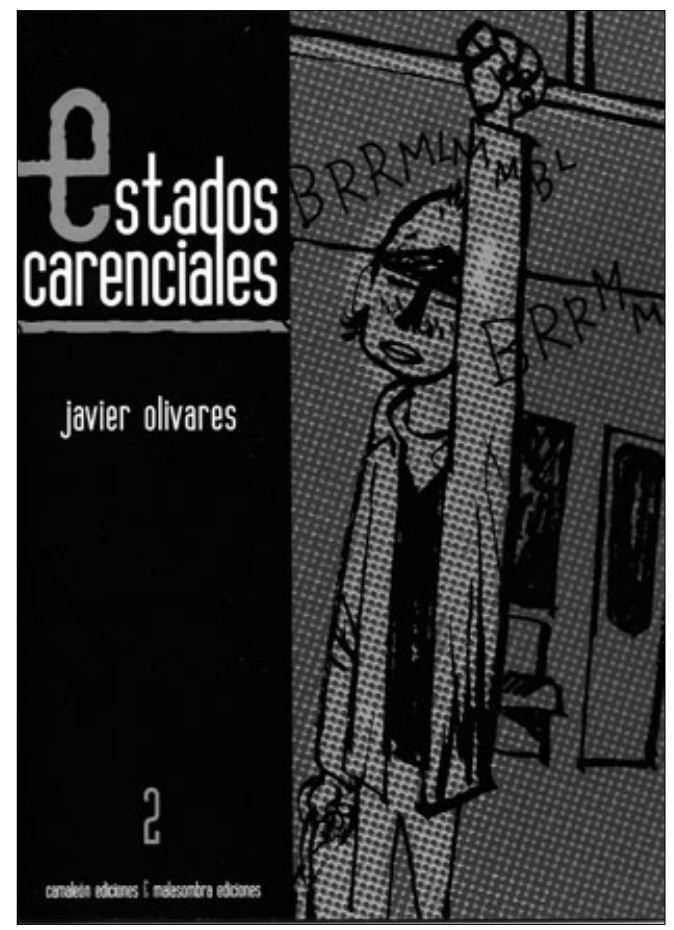

Imagen 3. Estados carenciales de Javier Olivares, comic-book editado por Camaleón-Malasombra, 1997. que habían sustentado revistas y álbumes. El comic-book o cuadernillo grapado se lo costeaba a veces el propio autor. 0 bien el editor se comprometía a pagarle tan solo el porcentaje por ejemplares vendidos, de modo que sumaba unos costes de producción bajos y un compromiso económico tasado con el autor. Pequeñas editoriales como Dude, Subterfuge, Under Cómic 0 La Factoría de Ideas emplearon el mismo formato y el mismo sistema editorial.

Las editoriales de cómic más asentadas adoptaron también el formato de comic-book, que pasó a ser el de la mayor parte del material importado que comercializaban, para explorar las posibilidades de la producción propia. Planeta DeAgostini inició en 1996 la efímera línea Laberinto, en la que publicó autores españoles. Norma empleó el cuaderniIlo sobre todo para reeditar material, lo mismo que Glénat, que probó también el género erótico. La Cúpula estableció el sello Brut, al que distinguió de los demás su cubierta más gruesa y en el que también publicó a algún autor español (Pons, Porcel y Sorni, 2007: 253-256).

El cuadernillo grapado fue, pues, el expediente a que acudieron de consuno quienes pese a todo seguían empeñados en dibujar cómics y quienes buscaban venderlos. Por lo general lo emplearon autores jóvenes y principiantes, más interesados en publicar que en cobrar. Pues dicho formato - de precio en portada notablemente menor que el de los álbumes y vendido en el reducido circuito de las librerías especializadas, más que en quioscos- y tales condiciones de edición no permitían al autor conseguir ingresos de profesional. Los historietistas de generaciones precedentes, de mayor edad y menor entusiasmo, en muchos casos con responsabilidades familiares, abandonaron el cómic o buscaron opciones profesionales en otros mercados con una industria digna de ese nombre. En el relevo de unos por otros tomó cuerpo lo que Altarriba ha descrito como un nuevo "ciclo" estanco de la historieta española:

Los autores que protagonizaron la renovación de los setenta y ochenta tampoco llegaron a atravesar el umbral de los noventa. Nombres tan imprescindibles en aquella época como García, Beá, Font, Ortiz, Leopoldo Sánchez, Fernando Fernández, Antonio Segura, Segrelles, Garcés, Beroy, Negrete, Estrada, Espinosa, Pons, Nazario, Martí, Montesol, Sento y así hasta prácticamente todos, se distanciaron o se apartaron definitivamente de la historieta, a pesar de que todos 
ellos se encontraban en plenitud creativa [...] Algunas de las figuras más importantes de aquellos años como Gallardo, Max, Torres, Prado, Pere Joan, Pellejero, De Felipe, Azpiri, Micharmut o Carlos Giménez continúan actualmente en contacto con el medio, pero sus colaboraciones son esporádicas, ofrecen con frecuencia formatos cercanos al libro ilustrado o vienen motivadas por la reedición o el relanzamiento de nuevos episodios de sus viejas series. Muy pocos son los que, como Javier Olivares, Calpurnio, Laura, Bernet o del Barrio mantienen una cierta regularidad de publicación. Todo indica que la senda cada vez más estrecha en alicientes y rendimientos económicos por la que se encamina la historieta solo permite esa precaria relación de quienes fueron sus más firmes pilares y ahora tan solo pueden conservar un interés circunstancial $y$, sin duda, algo nostálgico (Altarriba, 2001: 323-324).

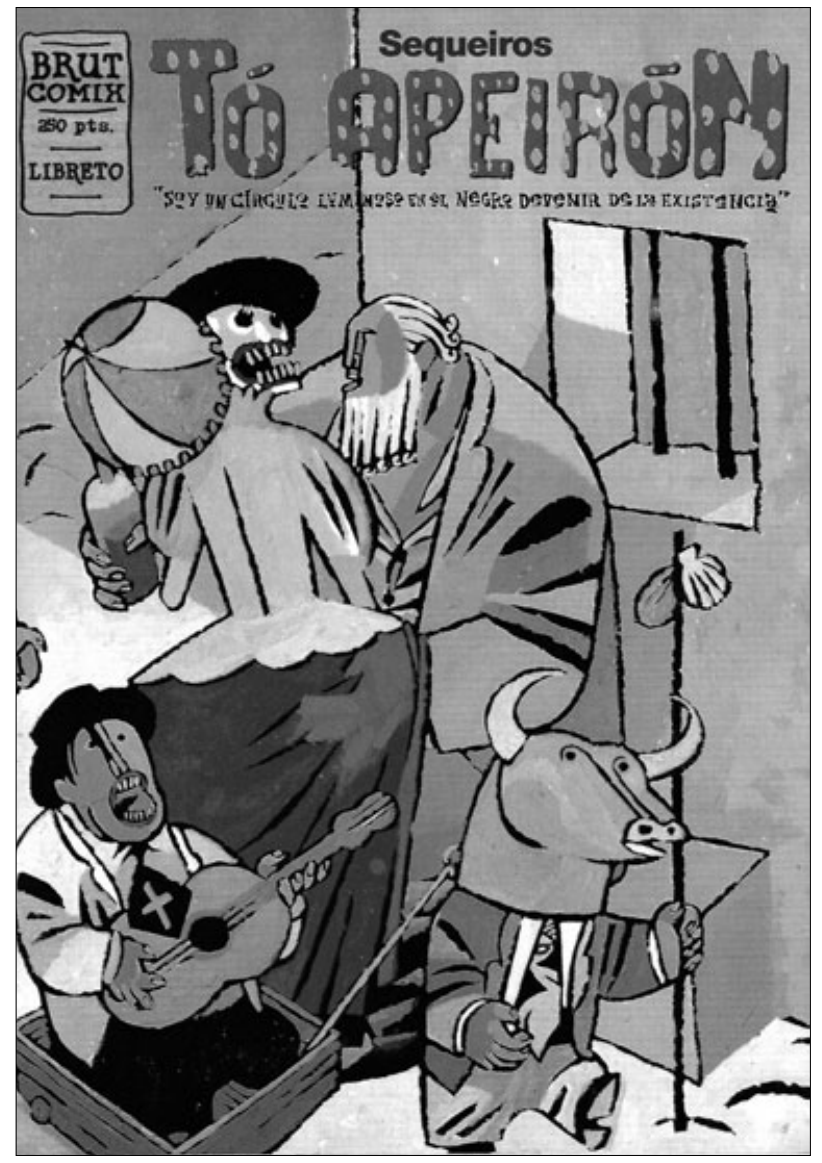

Imagen 4. Tó Apeirón de Sequeiros, comic-book de la colección Brut Comic, editada por La Cúpula, 1996.
A falta de estructuras industriales sólidas, el modesto y precario recurso de los cuadernillos, aprovechados para obras personales según el modelo del cómic alternativo 0 dibujados a imitación fiel de los comic-books comerciales americanos, permitió que se fuera constituyendo una nueva oleada de autores, un nuevo ciclo del cómic español, obligado de nuevo a reinventarse, para adaptarse a la penuria.

En este borrón y cuenta nueva, como suele suceder, las labores de creación, crítica y edición fueron realizadas a menudo por los mismos y emprendedores aficionados. Al igual que Camaleón editó cuadernillos de autor español y revistas de crítica, Dolmen fue primero revista y luego sello editorial; La Factoría de Ideas publicó cómics y una revista "sobre tebeos", El pequeño Nemo (1999-2004); Under Cómic publicó sucesivamente las revistas críticas Volumen (1999-2000) y

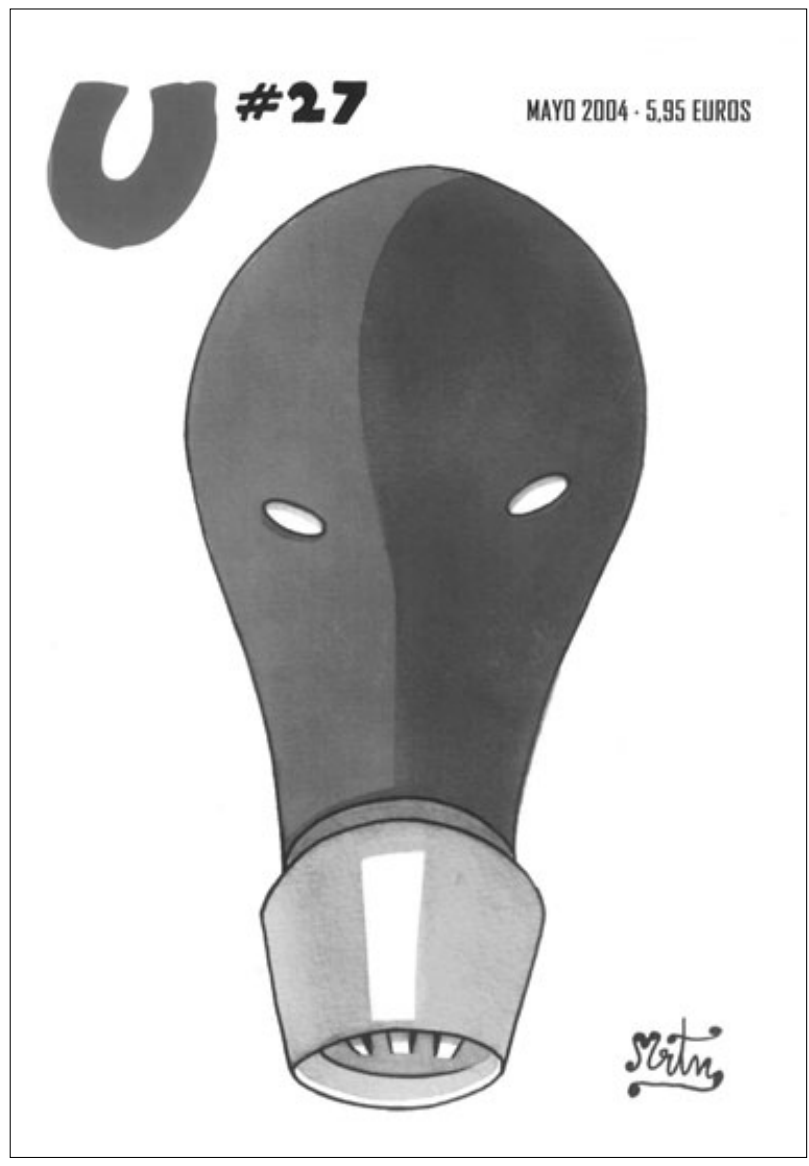

Imagen $5 . \mathrm{U}, n^{\circ}{ }_{27}$, el último de la revista, mayo de 2004. 
La guía del cómic (2001-2005); Astiberri, cuando se propuso editar cómics, creó su propia revista de información y crítica, Trama (2001-2005) (Díaz de Guereñu, 2006a).

De la generosa nómina de revistas informativas y críticas de este periodo destaca por su ambición $U$ (27 números, 1996 2004), que primero se llamó U, el hijo de Urich, por derivar del fanzine fotocopiado de dicho nombre, y que editaron sucesivamente varios sellos (Camaleón, La Factoría de Ideas) o sus propios responsables. La dirigieron solos o conjuntamente Santiago García, David M uñoz y Óscar Palmer, y, como resultado de su creciente número de páginas (la última salida sumó 192), abandonó la grapa a favor del lomo encolado a partir de su no 14 (enero de 1999). Destacaron entre sus contenidos las extensas entrevistas a autores, en particular españoles 0 hispanos, que fueron monopolizando dicho núcleo de la publicación (el último foráneo que ocupa portada es Kyle Baker, no 19, marzo de 2000) y a quienes dedicó además entrevistas breves, artículos, portafolios. Prestó atención preferente, así, a Prado, Víctor M ora, Daniel Torres, Horacio Altuna, J uan Giménez, Hernéndez Cava, Jordi Bernet o Miguel Ángel Martín.

La importancia de las revistas críticas en este periodo no es menor, pues contribuyeron decisivamente a establecer el canon del cómic tal como lo entendía la nueva generación de aficionados y creadores. Gustos e influencias de los autores, informaciones y opiniones de los críticos fueron dibujando las coordenadas actuales del medio. Tras la desaparición de casi todas las cabeceras impresas, con la excepción ya anotada de Dolmen, dicha labor la vienen realizando los blogs a través de Internet. Es imposible catalogarlos, dada su fugacidad, como lo es medir la influencia de las revistas impresas o de las compuestas en la red, pero es indudable que han servido para difundir nombres y obras que forman parte del paisaje de la historieta en estos inicios del siglo XXI. Y la permeabilidad de estas revistas a los conceptos críticos que operaban en el mercado norteamericano marca la orientación del nuevo canon crítico, ya desligado de la preferencia por el formato álbum y la tradición europea.

\section{REVISTAS DE AUTOR}

Pero la modesta grapa no fue el único expediente. En 1995 también se publicó el primer número de la revista Nosotros somos los muertos. La cabecera nació como fanzine fotocopiado en 1993 de un arranque del dibujante Max, que, asqueado por la indiferencia general ante las masacres en los Balcanes, dibujó una historieta corrosiva de ese título (Max, 2007). A él se sumó Pere Joan y ambos decidieron luego fundar su propia revista, que, con periodicidad insegura, soporte editorial cambiante (Inrevés, Sinsentido) y en diversos tramos, publicó 15 números hasta 2007, rotulados NSLM. Su modelo fue la revista RAW (1980-1991), editada por Art Spiegelman y Françoise Mouly. Como ella, NSLM procuró reunir lo más atrevido e interesante del cómic nacional e internacional. De tamaño grande $(23 \times 30,5 \mathrm{~cm})$, aspecto editorial cuidado -un centenar de páginas en buen papel, impreso en parte en color y encuadernado con lomo- y contenido experimental, publicó, junto a los grandes nombres del cómic de vanguardia internacional (los Spiegelman, Ware, David B., Doucet...), a muchos españoles: Javier Olivares, Martí, Santiago Sequeiros, Alex Fito, Miguel Brieva, Miguel B. Núñez,
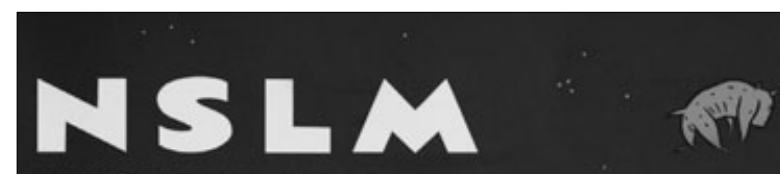

NOSOTROS SOMOS LOS MUERTOS \#IS

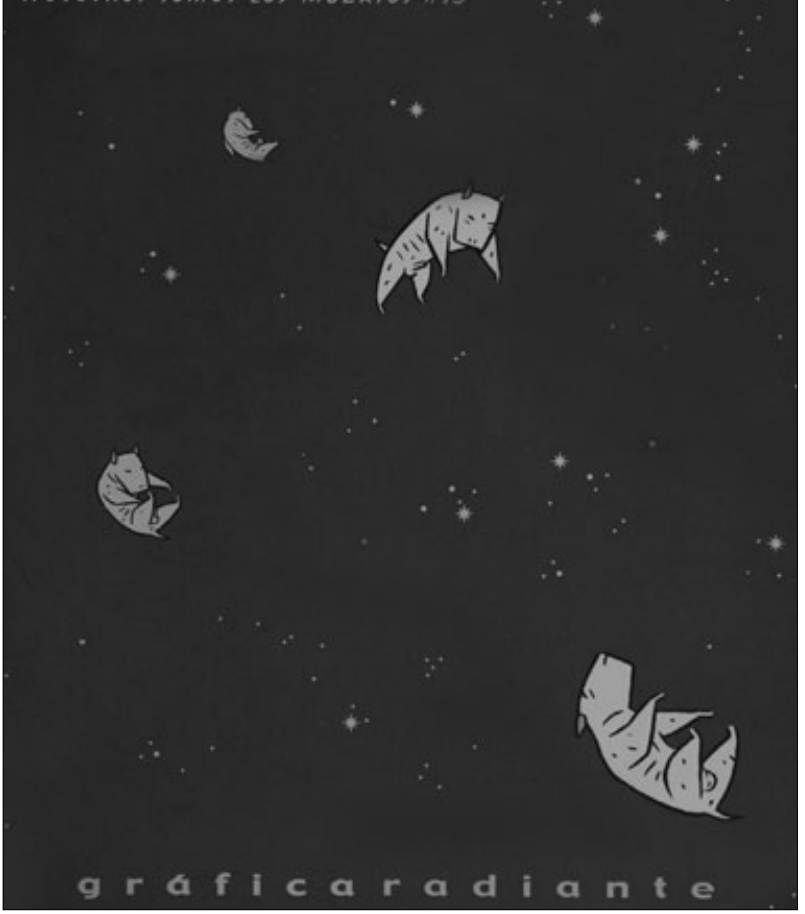

Imagen 6. NSLM, $n^{0} 15,2007$.

ARBOR CLXXXVII 2EXTRA 2011 209-220 ISSN: 0210-1963

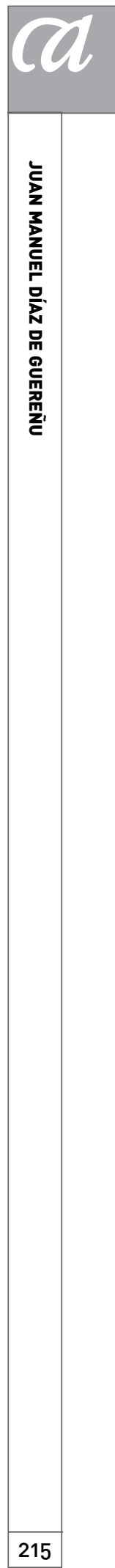


Sonia Pulido, Keko, Ágreda, Paco Alcázar, Santiago García y Pepo Pérez, entre otros.

NSLM trazó un camino al margen de las estrategias comerciales, definido tan solo por la voluntad expresiva de unos autores que daban el cómic por medio fallido en nuestro mercado editorial, pero lo reivindicaban aun así como lenguaje de posibilidades expresivas dignas de ser exploradas. Quiso mostrar la vitalidad del arte del cómic ofreciendo una plataforma para las nuevas formas de entender la narración visual. El nombre de cabecera, en el panorama de la historieta española, siempre en condición agónica, adquirió resonancias burlonas. No era, desde luego, la primera vez que un grupo de autores españoles unía sus fuerzas para gestionar su propia publicación (Gálvez y Fernández, 2004: 31-36), pero sí la primera en que su propósito declarado fue proclamar su autonomía de artistas con respecto a los requerimientos del mercado.

Con un precio en portada que llegó a ser de 16 euros, la revista no proporcionó ganancias a sus editores, sino que les resultó habitualmente onerosa. Las escasas ventas y el esfuerzo económico que representó fueron razones para que NSLM dejara de publicarse.

No obstante, añadió un nuevo modelo al bullente mundiIlo de la autoedición, por lo general tan ágil y precario como los fanzines o revistas de aficionados, resignados a fotocopia y grapa, a tiradas cortas y distribución local. A tales recursos deben su vitalidad fugaz ese tipo de publicaciones, que proliferaron y se esfumaban con rapidez (solo para el ámbito del País Vasco y desde los setenta, el catálogo Fanzinoteka lista medio millar, censo sin duda incompleto). En los últimos años, la apuesta por el mínimo gasto ha conducido estas formas efímeras de la autoedición a las páginas de Internet.

Max y Pere Joan concibieron NSLM de modo muy distinto, compartiendo sin duda el proyecto de $R A W$, que, según Spiegelman, fue un "intento de redefinir lo que un cómic puede ser" aprovechando la "tensión entre un formato elegante y un medio al que solemos considerar subliteratura" (2007: 25-26). Se emparentó visiblemente más con la revista de arte que con el modesto fanzine, pues sus características editoriales por sí mismas constituyeron una reivindicación de la estatura estética y cultural del medio. Abrió así la vía a revistas más o menos elegantes, aunque algunas de ellas retuvieron la denominación fanzine para subrayar su carácter no profesional (y en última instancia no comercial). Las editaron autores de cómic que se cuidaron de poner la cualidad singular de los contenidos por encima de las ventas.

Juanjo el Rápido fue promotor incansable de cabeceras, en las que ejerció de autor y coordinador. Publicó sucesivamente Idiota y Diminuto, que alcanzó los 15 números entre 1997 y 2001, el último doble, en blanco y negro y color; TOS, "fanzine de historietas" (2002-2005), que publicó 13 números aproximadamente trimestrales y de entre 80 y 192 páginas impresas en monocromía con los sellos editoriales de Sinsentido y Astiberri; y Humo (2005-2007), que salió de imprenta con periodicidad trimestral en ocho ocasiones, ofreciendo entre 48 y 96 páginas en blanco y negro de un formato inusual $(21 \times 21 \mathrm{~cm})$. Tanto TOS como Humo, por su volumen y su encuadernación con lomo, se aproximaron más a formatos de libro que a los usuales de revista.

De dimensiones menores fue Fanzine Enfermo (solo $15 \mathrm{x}$ $21 \mathrm{~cm}$ ), que promovieron Alberto Vázquez, Dani García y Félix Díaz, y publicó y distribuyó un colectivo de dibujantes. Salió en ocho ocasiones entre 2004 y 2007, para servir al desarrollo de los autores, y ha sido reeditado en un volumen que añade un no 9 (2009). Miguel B. Núñez, Paco Alcázar y Miguel Brieva publicaron tres números de Recto (20022004) al abrigo de tres editoriales diferentes (Undercomic, Doble Dosis y Astiberri). Brieva, en fin, llevó a su límite lógico estas publicaciones de autor al dibujar y editar su propia revista, Dinero, que con el lema "Revista de poética financiera e intercambio espiritual" publicó cinco números (20012005) coeditados con Doble Dosis (hay reedición íntegra, que añade color al bitono de la original: Brieva, 2008).

Estas cabeceras y otras han aportado al cómic español una terca voluntad de creación original y servido de vivero para autores decididos a explorar a su modo las fronteras expresivas del medio. El tiempo dirá cuántos y cuáles entre ellos alcanzan a desplegar obra significativa, pero, independientemente de la fertilidad a largo plazo del fenómeno, es claro que revistas y fanzines como herramientas de afirmación de la autoría y reivindicación estética del medio caracterizan este periodo y marcan un nuevo desarrollo de la concepción del cómic como lenguaje artístico que germinó en periodos precedentes. 
Un tipo de gestión similar, aunque una orientación menos experimental y características formales más próximas a las de las revistas de décadas pasadas tienen otras cabeceras surgidas en el periodo. Dos veces breve, que edita José Vicente Galadí bajo el sello Ariadna, ha llegado al no 21 de su segunda época en mayo de 2010 ofreciendo entre 52 y 60 páginas en blanco y negro y color con historias cortas de autores españoles, habitualmente agrupadas en torno a un tema monográfico. Dib-buks edita El Manglar, codirigida por el editor Ricardo Esteban y el dibujante M anuel Bartual. Ha publicado 12 números de 98 páginas en color con historias largas por entregas e historias cortas de autores españoles y extranjeros, entrevistas y reseñas. La periodicidad insegura y el no estar integradas en un sistema de producción editorial asentado en el que servir de primer escaparate de venta distinguen a estas revistas de las de los ochenta. Por lo mismo, aunque prefieren materiales menos experimentales que las precedentes, se sitúan en un terreno medio entre el cómic de autor y el comercial.

Las revistas de cómics del periodo, en definitiva, ya no responden a una demanda lectora con materiales aderezados para el consumo mayoritario, sino que derivan más bien de la propensión de los autores a laborar su propia expresión y a ofrecer búsquedas y hallazgos a un lector posible. En este sentido, su función -como su funcionamiento- es más parecida a la de las revistas literarias o poéticas minoritarias que a la de las revistas de quiosco. En definitiva, no organizan el campo de la historieta en términos económicos, aunque sí contribuyen a definir el medio como lenguaje, sus recursos y su valor.

\section{OTROS EDITORES}

En 1995, en fin, Paco Camarasa y MacDiego fundaron como por broma una editorial en Valencia, Joputa, que inesperadamente abrió otros caminos a la producción y edición de cómics en España.

Entonces como ahora dominaban el mercado del cómic en España Planeta DeAgostini y Norma, a las que se sumaron luego Glénat y Panini. Los porcentajes del negocio que ha ocupado cada una durante estos años han variado de acuerdo con el peso de las respectivas licencias de publicación de material importado, es decir, según el éxito de tal comic-book o manga, de tal serie o personaje de Marvel o DC protagonista del estreno cinematográfico de turno 0 de tal otro adaptado a la serie de animación televisiva preferida del público. Dicho material traducido se lleva la parte del león del negocio del cómic entre nosotros, y las citadas editoriales acaparan habitualmente en torno a los dos tercios de los títulos publicados. El resto lo publica un enjambre de pequeñas, muy pequeñas u ocasionales editoras de cómics, que acometen la edición más arriesgada, exigente 0 de horizonte comercial menos claro. Jesús Cuadrado enumera para los años 2007 y 2008 más de 90 (Peonza, 2009: 88-89).

Temas y formas de éxito impregnan al cómic español, crean escuela, y es tradición que, a falta de industria local, dibujantes españoles se incorporen como profesionales a industrias foráneas más fuertes y los leamos luego traducidos. En el periodo precedente trabajaban sobre todo para editoriales europeas, en particular francófonas, a través de agencias o de forma individual; en la actualidad, el mercado de referencia es el americano, más permeable por su carácter industrial a dicha incorporación. Los dibujantes, lo mismo que los lectores españoles, prefieren el comic-book al álbum franco-belga. Azpitarte ha documentado la labor de un primer grupo de profesionales (Carlos Pacheco, Salvador Larroca, Pasqual Ferry y Paco Díaz) y enumera otros que los siguieron desde finales de los noventa: Rafa Fonteriz, Ramón F. Bachs, J avier Pulido, Ángel Unzueta, Germán García, Kano y otros, hasta sumar una treintena (Azpitarte, 2006: 283-286).

Es la alternativa a una industria española que no ofrece sino por excepción trabajo profesional. Los análisis de la edición siguen aportando datos coincidentes año tras año: solo una porción menor de lo editado en la última década, un 10 por ciento aproximadamente, es de producción propia. En el desarrollo de dicha producción, de los formatos que ha ido adoptando y del valor que se le atribuye han tenido su peso J oputa y sobre todo Edicions de Ponent, que le sucedió en 1998.

En realidad, el sello J oputa no figuró en ninguno de los libros que editaron Camarasa y MacDiego, que prefirieron dejarse de bromas y firmarlos con sus nombres (Pons, Porcel y Sorni, 2007: 264). El sello definitivo, Edicions de Ponent, lo gestó Camarasa en solitario con el propósito de "reivindicar la labor del autor nacional" (Mesón, 2006) y prestar particular atención a la "calidad en cuanto a forma y contenidos" (Peonza, 2009: 190). Lo que distinguió su labor desde un principio fue, en efecto, la atención a los detalles editoriales. Formato y 
características físicas procuraron hacer de cada título un objeto estéticamente apreciable por sí mismo, en contraste con el mal gusto y la incuria habituales en la edición de cómic comercial, lo que le ganó numerosos premios a la edición, nacionales e internacionales.

Ponent ha incluido en su catálogo obras de lo más sustantivo entre los autores españoles, consagrados o principiantes, en particular los procedentes de su área geográfica próxima. Figuran en él Sento, Micharmut, Miguel Calatayud, Pere Joan, Max, Cifré, El Cubri, María Colino, Ricard Castells, Santiago Valenzuela, M auro Entrialgo, Luis Durán, Pablo Auladell y muchos otros. Constituyen el grueso de su producción.

Ponent edita con regularidad, un título por mes, a veces dos. Las tiradas suelen ser cortas, de 1.000 ejemplares, y en consecuencia los ingresos de los autores, de poca monta. Habitualmente reciben su porcentaje sobre ejemplares vendidos y en las colecciones de encargo, Mercaty El cuarto oscuro, 0 en otros casos de excepción, adelantos sobre los derechos de parte 0 toda la edición. Tampoco los ingresos de la editorial permiten considerarla un negocio, sino más bien un proyecto motivado por amor al arte del cómic. Pero, aunque no ha proporcionado base industrial para que el editor o los historietistas se profesionalicen, ha ofrecido a estos una salida editorial digna y una alternativa de calidad al formato del cuadernillo grapado para obras más extensas y de mayor ambición. Se ha situado así en un terreno compartido con las revistas de autor del estilo de NSLM.

Ponent estableció en España un modelo editorial similar al de algunos independientes americanos y franceses (Fantagraphics, Drawn \& Quarterly, L'Association) y mostró que era posible publicar cómics de otra manera, como se editan los buenos libros. Siguieron su estela otros sellos que también se han señalado por buscar la dignidad o incluso la elegancia editorial, entre ellos Sinsentido (1999), Astiberri (2001), Ponent Mon (2003) o Apa-Apa (2008). La labor conjunta de todos ellos ha modificado la percepción del cómic como producto editorial, alejándolo del cuadernillo barato y aproximándolo al libro -cuyos formatos de edición ha adoptadoe incluso a las versiones más cuidadas de este. La relativa fortuna económica y de prestigio de tales prácticas ha cambiado las de las editoras comerciales en algunos de sus productos y ha propiciado que editoriales generalistas como Alfaguara, SM o Random House Mondadori emprendan también la edición de cómics de modo más o menos regular.
El éxito reciente de la denominación "novela gráfica", probablemente el fenómeno internacional más notable de la evolución del cómic en la última década, deriva de la conjunción de obras formal y temáticamente más ambiciosas, nacidas de una clara conciencia de autor, y de ediciones más acordes con tal ambición, conjunción que ha ganado para el medio un prestigio cultural que nunca antes había conocido (García, 2010). El cómic español también participa de dicho fenómeno. Signo de la nueva valoración del medio es desde 2007 el Premio Nacional del Cómic que otorga el Ministerio de Cultura.

Ha contribuido a asentar esta nueva percepción del cómic la incorporación de tales obras a otros puntos de venta en grandes superficies y librerías no especializadas y, con ella, la apertura a lectores no habituales de cómics. Señaló el

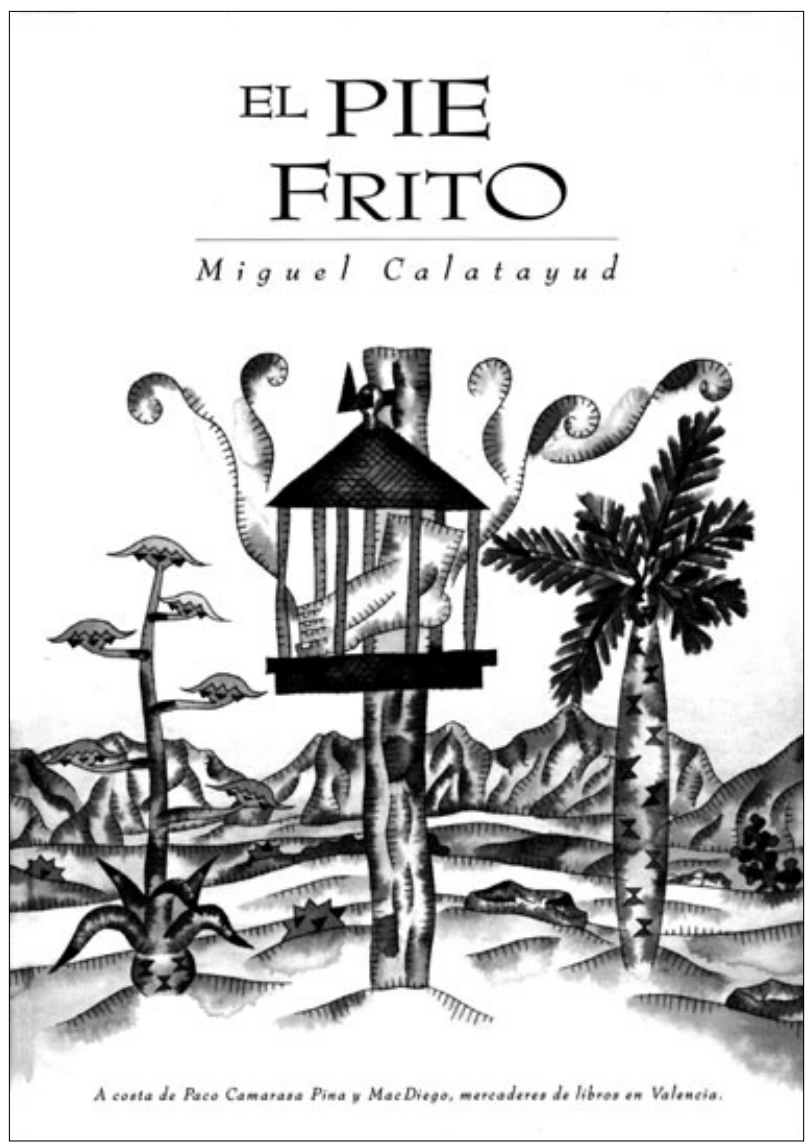

Imagen 7. El pie frito de Miguel Calatayud, "A costa de Paco Camarasa Pina y MacDiego, mercaderes de libros en Valencia" (1997). 
camino la cadena internacional Fnac, que en 1993 abrió su primera tienda en Madrid y que hoy dispone de una red de una veintena en todo el país. Habituada a los modos de comercializar bande dessinée en el mercado francés, la Fnac incluyó muy pronto los cómics de formato equiparable al libro en su oferta, práctica que han seguido después otras cadenas de grandes superficies o librerías. La Fnac convoca también desde 2007, con la editorial Sinsentido, un premio de novela gráfica a fin de "promover e incentivar la producción literaria en el ámbito del cómic".

Las nuevas prácticas editoriales han encontrado así acceso a un público lector más amplio, al que caracterizan un poder adquisitivo mayor que el del comprador habitual de tebeos de quiosco y un hábito de consumo regular de productos culturales. Astiberri declara, por ejemplo, que su tarea editorial se dirige a "un público adulto independientemente de su edad, formado y no necesariamente habituado a la historieta" (Peonza, 2009: 186). Todo indica que el mercado posible del cómic crece.

Sin embargo, a juzgar por lo que dicen los autores en entrevistas y entradas o comentarios de blog, no parece que este nuevo paradigma del cómic haya modificado todavía sustancialmente su situación. Alcanzan el estatuto de profesionales si consiguen contrato asalariado en la industria norteamericana o trabajan de modo regular para revista 0 diario. Si no, siguen creando historietas con la perspectiva de unos ingresos que no compensan la tarea, como autores empecinados en su tiempo libre, aunque el reconocimiento social y cultural de su obra ha mejorado de forma notoria. Horacio Altuna constata que los dibujantes sufren un "deterioro económico" creciente "desde los ochenta" (Fadip, 2009: 46). El análisis que hace Pepo Pérez en una entrada de blog de octubre de 2008 sobre las tarifas habituales en revistas, diarios y editoriales no deja lugar a cálculos optimistas para la gente del oficio (Pérez, 2008).

Con todo, el creador de cómics español de hoy conoce un campo de actividad más abierto que el de hace década y media. Por un lado, aunque la inmensa mayor parte del cómic editado en el país es importado, los compatriotas que trabajan más allá de la frontera han logrado prestigio de buenos profesionales de la industria y abierto esa posibilidad. Por otro, gracias a la tradición de las revistas y fanzines de autor y a la labor de las pequeñas editoriales, ha quedado asentada socialmente y reconocida culturalmente la noción de cómic de autor, que permite la creación de obras personales, formalmente más atrevidas y de contenido más denso. El autor que se embarque en la aventura de crear cómics tiene, pues, algún horizonte de publicación, aunque la compensación económica por su trabajo sea bien magra.

En este periodo no han dejado de aparecer jóvenes talentos, como David Rubín, Miguel Brieva, J. M. Ken Niimura, Javier de Isusi, Pablo Auladell, Paco Roca, Alberto Vázquez, Jali, Santiago Valenzuela, Clara Tanit, Alfonso Zapico, Fermín Solís, Álvaro Ortiz y tantos otros que, pese a todo, no abandonan, conscientes de que el arte de contar y contarse en viñetas que se empeñan en practicar conoce hoy un periodo de esplendor. Aunque la industria editorial apenas lo sostenga. Puede que una retribución mísera sea condición de su libertad de creadores. 0 a lo mejor no.
Recibido: 20 de septiembre de 2010 Aceptado: 2 de diciembre de 2010

\section{BIBLIOGRAFÍA}

AzPITARTE, Koldo (2006): Cómics made in Spain. Palma de Mallorca: Dolmen.

Brieva, Miguel (2008): Dinero. Barcelona: Random House Mondadori.

Díaz de Guereñu, Juan Manuel (2006a): Gratuita, no barata. Una historia de Trama (2001-2005). Vitoria: Atiza.

- (2006b): 30 x 30. Dimensiones de nuestra historieta. San Sebastián: Atiza- Gráficas Michelena.
Dopico, Pablo (2005): El cómic underground español, 1970-1980. Madrid: Cátedra. Enfermo (2009): Bilbao: Astiberri.

FADIP (2009): Observatorio de la ilustración gráfica. Informe 2008. Madrid: Federación de Asociaciones de llustradores Profesionales.

FANZINOTEKA (2009): Vitoria: Fundación Sancho el Sabio-Caja Vital.

Gálvez, Pepe y Fernández, Norman (2004): Nosotros somos los muertos. El arte 
de la resistencia. Gijón: Fundación Municipal de Cultura-Semana negra. GARCíA, Santiago y MuÑoz, David (1998): "La industria habla \# 1: La Cúpula" (entrevista a Hernán Migoya): U, el hijo de Urich. 11. Barcelona: Camaleón, julio, 16-22.

GARCíA, Santiago (1999): "La industria habla \# 3: Dude" (entrevista a Andrea Parissi). U, el hijo de Urich. 16. Madrid: La Factoría de Ideas, mayo, 2427.

García, Santiago (2010): La novela gráfica. Bilbao: Astiberri.

García, Vicente (2004): "Dolmen \# 100. Diez años no son nada". Dolmen, 99-100. Palma de Mallorca, mayo, 111-115.

GuIRAL, Antoni (2006): “Mnie... ¿Qué hay de nuevo, viejo? Una aproximación muy precaria (como todo en esta vida) al mercado de cómics español de 2005". Comic Tecla, 18, enero-febrero, 1-5. http://www.l-h.es/biblioteques/163503_2.aspx
Harguindey, Breixo (2006): "El estado del cómic", en Anuario de la historieta 2005. Asociación de Autores de Cómic de España. Valencia: sin ed., s.f., 79-86.

Martínez, Rafa (1995a): "Éste que tenéis en las manos es el penúltimo número de Cimoc", en Cimoc, 175. Barcelona: Norma: 2.

MartíneZ, Rafa (1995b): "Y 176", en Cimoc, 176. Barcelona: Norma, 1.

Max (2007): "Nosotros somos los muertos", en Como perros! ( $2^{\mathrm{a}} \mathrm{ed}$.). BarceIona: La Cúpula: 43-52.

MEsón, Javier (2006): "Entrevista con Paco Camarasa de Edicions de Ponent". 22 de noviembre. http://elcoleccionistadtbos.zonalibre.org/archives/099277.html

Peonza (2009): Monográfico El cómic 88/89. Santander: Asociación Cultural Peonza, marzo-junio.

Pérez, Pepo (2008): "El negocio de dibujar cómics". Entrada del 23 de octubre. http://concdearte.blogspot.com/200 8/10/el-negocio-de- dibujar-cmicii_23.html. Recogida también en FADIP (2009): Observatorio de la ilustración gráfica. Informe 2008. Madrid: Federación de Asociaciones de Ilustradores Profesionales: 47-49.

Pons, Álvaro (2008): "Los tebeos en España en el 2007", en Anuario de la historieta 2007. Asociación de Autores de Cómic de España. Barcelona: Gráficas Gispu, 60-65.

- (2010): "Los números del 2009". Entrada del 19 de mayo de 2010. http://www.lacarceldepapel. com

Pons, Álvaro; PORCEL, Pedro y SORNI, Vicente (2007): Viñetas a la luna de Valencia. La historia del tebeo valenciano (19652006). Alicante: Edicions de Ponent.

Serrano, José A. (2009): "Kiss Comix (revista)", agosto. http://www. guiadelcomic. com/autores/kiss-comix/revista.htm

TRAma (2002): "Los jóvenes autores de El Jueves" (entrevista). Trama 16. Bilbao: Astiberri, 4-14. 